\title{
Assessment of Data Assimilative Ocean Models in the Gulf of Mexico
}

\section{using Ocean Color}

\author{
Eric P. Chassignet ${ }^{1}$, Harley E. Hurlburt ${ }^{2}$, Ole Martin Smedstad ${ }^{3}$, Charlie N. Barron ${ }^{2}$, Dong S. Ko ${ }^{2}$, Robert \\ C. Rhodes ${ }^{2}$, Jay F. Shriver ${ }^{2}$, Alan J. Wallcraft ${ }^{2}$, and Robert A. Arnone ${ }^{2}$ \\ ${ }^{1}$ RSMAS/MPO, University of Miami, Miami, Florida \\ ${ }^{2}$ Naval Research Laboratory, Stennis Space Center, Mississippi \\ ${ }^{3}$ Planning Systems Inc., Stennis Space Center, Mississippi
}

This paper illustrates the value of SeaWiFS ocean color imagery in assessing the ability of three data-assimilative ocean models (configured in five prediction systems) to map mesoscale variability in the Gulf of Mexico (i.e., the Loop Current and associated warm and cold eddies) and in helping to diagnose specific strengths and weaknesses of the systems. In addition, the study clearly illustrates that biological responses of the surface waters are strongly linked to the physical events and processes.

\section{INTRODUCTION}

An accurate depiction of currents and associated features such as mesoscale eddies, fronts, and jets, is essential to any ocean forecasting system. The ability to use high-resolution ocean models for data assimilation and forecasting is critical to the development of these nowcast/forecast systems. Applications include assimilation and synthesis of global satellite surface data, ocean prediction, optimum track ship routing, search and rescue, antisubmarine warfare and surveillance, tactical planning, high resolution boundary conditions that are essential for even higher resolution coastal models, sea surface temperature for long range weather prediction, inputs to shipboard environmental products, environmental simulation and synthetic environments, observing system simulations, ocean research, pollution and tracer tracking, inputs to water quality assessment, and so forth.

Since most high horizontal resolution observational data (i.e., altimetry and sea surface temperature) are assimilated in these systems, there are very few independent observations with sufficient coverage to be useful in assessing the ability of ocean prediction models to map mesoscale ocean features. In this paper, we assess the performance of several data assimilative ocean model systems against independent ocean color measurements in the Gulf of Mexico. The near-surface biological and optical properties, derived from ocean color imagery, provide an excellent evaluation method for assessing the capability of data-assimilative numerical models to define the spatial and temporal mesoscale variability. Although these properties are non-conservative and are influenced by biological processes, these optical gradients are an independent data set with the ability to track and monitor mesoscale features such as warm and cold core rings, coastal filaments and the Loop Current position. Feature tracking using a time series of these independent observations in the Gulf of Mexico is a very effective way to compare different ocean prediction systems.

Because of the logistics associated with routine analysis and prediction, most large-scale ocean prediction systems are located within government centers. Recently, the Global Ocean Data Assimilation Experiment (GODAE) has provided an international framework for such systems to be evaluated and intercompared. The rationale for restricting ourselves to the systems compared in this paper (see section 3 for details) is that they all use the same atmospheric forcing and assimilate the same observational data. This allows us to evaluate the performance of the systems independently of the choice made for external inputs (atmospheric forcing or ocean data input). Another example of a Gulf of Mexico data assimilative system is discussed by Kantha et al. in this volume. 


\section{OCEAN COLOR}

The data set used to evaluate the forecasting systems consists of satellite measurements of ocean color data obtained by the Sea-viewing Wide Field-of-view Sensor (SeaWiFS) in orbit on the OrbView-2 (formerly SeaStar) platform. Ocean color satellites such as SeaWiFS and MODIS provide new capability to quantitatively monitor biological and optical properties of the near surface ocean [Arnone and Parsons, 2004]. Accurate sensor calibration and atmospheric correction are required in order to detect the subtle changes in ocean color which are used to uncouple the in-water components.

The apparent color of the ocean, which can range from deep blue to varying shades of green and ruddy brown, is primarily determined by the concentration of substances and particles in the euphotic (lighted) zone of the upper ocean. Living phytoplankton (which contain chlorophyll and associated photosynthetic pigments), inorganic sediments, detritus (particulate organic matter), and dissolved organic matter all contribute to the color of the ocean. When visible light from the sun illuminates the ocean surface, it is subject to several optical effects. Foremost among these effects are light absorption and scattering. Spectral absorption selectively removes some wavelengths of light while allowing the transmission of other wavelengths. In open ocean waters absorption is primarily due to the photosynthetic pigments (chlorophyll) present in phytoplankton, whereas in coastal waters additional absorption processes occur from the absorption of detritus and colored dissolved organic matter (CDOM). Following spectral absorption, backscattered light (resulting from organic and/or inorganic particulate matter suspended in the water) produces a modified light radiating from the ocean surface, the "water-leaving radiance," i.e., the ocean color. Spaceborne radiometers such as SeaWiFS measure the spectral radiance intensity at specific wavelengths. These measurements are used to determine quantitative constituents in the water column that interact with visible light, such as chlorophyll. Additional components of the absorption and backscattering light field can be uncoupled from the ocean color signatures, but are beyond the scope of this paper. We used the chlorophyll component in this study because it is the dominant contributor to the ocean color in open ocean processes.

The chlorophyll products from SeaWiFS represent the integrated near-surface concentrations within the first attenuation length of visible light $(490 \mathrm{~nm})$. For Loop Current waters, this is approximately 20 meters, whereas in turbid coastal areas, this is reduced to as little as two to three meters. This product is different from a satellite SST product that only senses the skin temperature and responds to diurnal heating. Ocean color products can be used to detect ocean features throughout the year, which is especially useful during the summer months when the SST in the Gulf of Mexico is nearly isothermal and cannot be used for feature detection. However, chlorophyll concentrations can change rapidly through phytoplankton growth and decay and through vertical movements of phytoplankton into or out of view of the satellite.

The SeaWiFS mission is a public-private partnership between NASA and Orbital Sciences Corporation. SeaWiFS was launched in August 1997 and acquires approximately 15 pole-to-pole orbital swaths $(\sim 2800$ $\mathrm{km}$ wide) of data per day, and approximately $90 \%$ of the ocean surface is scanned every two days. The SeaWiFS ocean data set used in this effort was collected and processed daily for the Gulf of Mexico at the Naval Research Laboratory (NRL) receiving site using the Automatic Processing System developed for the Naval Oceanographic Office to provide operational products. Atmospheric correction and in-water chlorophyll algorithms (OC4) were applied [Arnone et al., 1998; O'Reilly et al., 1998] as extensions of the NASA algorithms to address the coastal waters. Note that the OC4 algorithm uses a simple ratio of spectral channels at 443, 488, 520 and $550 \mathrm{~nm}$ of the water-leaving radiance to determine chlorophyll. This simple algorithm is closely associated with total absorption coefficient, which in the open ocean is closely associated with chlorophyll concentrations [Lee et al., 1998]. However, for other locations, such as in coastal areas, the algorithm significantly overestimates chlorophyll, and the values are closely associated with the total absorption coefficient rather than chlorophyll.

Because the majority of visible imagery is limited by cloud cover, the latest pixel composite is created daily to represent the optimum coverage of ocean features within the last 7 days. The compositing technique provides the most recent image of ocean conditions each day. A seven-day period effectively removes cloud cover and still retains consistency in feature tracking to monitor the slower mesoscale ocean features for comparison with the model results.

Ocean color can change rapidly in response to 1) open ocean biological processes occurring at daily time scales and 2) subduction of surface chlorophyll below the satellite detection depth. Phytoplankton concentrations can double within a day provided optimum light and nutrient availability. More traditionally, chlorophyll response in upwelling regions occurs on time scales of 4-7 days as the bloom matures, and blooms with a continuous nutrient supply can remain observable for months. A similar response occurs in frontal boundaries where a steady increase in chlorophyll is observed with 
constant frontal upwelling. Similarly, blooms can degrade rapidly in 4-7 days as nutrients are rapidly depleted. However, these daily color changes mainly influence the magnitude of the chlorophyll concentration, whereas the location of the fronts and eddies is driven primarily by the circulation. Therefore, the use of the seven day composite provides a reasonable location of the mesoscale features which are identified by the models.

\section{THE DATA ASSIMILATIVE OCEAN MODELS}

The three data assimilative ocean models (configured into five prediction systems) discussed in this paper are designed for nowcasting and forecasting of the mesoscale, large scale, and upper ocean. Two of the prediction systems use the NRL Layered Ocean Model (NLOM) [Hurlburt and Thompson, 1980; Wallcraft et al., 2003] and two use the Navy Coastal Ocean Model (NCOM) [Barron et al., 2004, 2005, Kara et al, 2005], all four developed at the Naval Research Laboratory, Stennis Space Center. The final system is based on HYCOM (HYbrid Coordinate Ocean Model) [Bleck, 2002; Chassignet et al., 2003; Halliwell, 2004] which has been developed by a community effort (http://hycom.rsmas.miami.edu) supported by the National Ocean Partnership Program (NOPP). The rationale for restricting ourselves to these systems is that they all use the same atmospheric forcing from the Fleet Numerical Meteorology and Oceanography Center (FNMOC) Navy Operational Global Atmospheric Prediction System (NOGAPS) [Hogan and Rosmond, 1991; Rosmond et al., 2002], and assimilate the same observational data, the altimeter sea surface height (SSH) as well as the operational 1/8 ${ }^{\circ}$ MODAS [Modular Ocean Data Assimilation System; Fox et al., 2002] sea surface temperature (SST) analyses of AVHRR (Advanced Very High Resolution Radiometer) data. This allows us to evaluate the performance of the systems independently of the choice made for external inputs (atmospheric forcing or ocean data input).

\subsection{The Numerical Models}

NLOM was designed for use in a first generation global ocean prediction system by allowing high horizontal resolution at much lower computational cost than other models [Hurlburt, 1984]. NLOM has been configured globally from $72^{\circ} \mathrm{S}$ to $65^{\circ} \mathrm{N}$ at $1 / 16^{\circ}$ and $1 / 32^{\circ} \quad(\sim 7$ and $3.5 \mathrm{~km}$ mid-latitude, respectively) resolution. However, NLOM has only 7 layers in the vertical, including the mixed layer, and excludes the Arctic and most shallow water (i.e., the lateral boundaries usually follow the $200 \mathrm{~m}$ isobath.).
Global NCOM was designed to complement NLOM by covering these regions and using much higher vertical resolution, but with coarser $1 / 8^{\circ}$ (15-16 km midlatitude) horizontal resolution. NCOM has a mixed $\sigma-\mathrm{z}$ vertical coordinate [Barron et al., 2005] where terrainfollowing $\sigma$ coordinates are used when the bottom depth is $<137 \mathrm{~m}$ in the current global configuration. This configuration has 40 levels in the vertical with vertical resolution $\sim 1$ m very near the surface for fine resolution of the mixed layer. Global NCOM encompasses the open ocean to $5 \mathrm{~m}$ depth in a curvilinear global model grid with $1 / 8^{\circ}$ latitudinal grid spacing at $45^{\circ} \mathrm{N}$. The grid extends from $80^{\circ} \mathrm{S}$ to a complete Arctic cap with grid singularities mapped into Canada and Russia. A regional configuration of NCOM is discussed in section 5 .

Recent model comparison exercises performed in Europe (DYnamics of North Atlantic MOdels DYNAMO) [Willebrand et al., 2001] and in the U.S. (Data Assimilation and Model Evaluation Experiment DAMÉE) [Chassignet et al., 2000] have shown that no single vertical coordinate (depth, density, or terrainfollowing sigma) can by itself be optimal everywhere in the ocean. Isopycnal (density tracking) layers are best in the deep stratified ocean, z-levels (constant fixed depths) are best used to provide high vertical resolution near the surface within the mixed layer, and sigma-levels (terrain-following) are often the best choice in shallow coastal regions. HYCOM combines all three approaches by choosing the optimal distribution at every time step. The hybrid coordinate is one that is isopycnal in the open, stratified ocean, but that makes a dynamically smooth transition (via the layered continuity equation) to terrain-following coordinates in shallow coastal regions, and to pressure coordinates in the mixed layer and/or unstratified seas. The capability of assigning additional coordinate surfaces to the oceanic mixed layer in HYCOM provides the option of implementing sophisticated vertical mixing turbulence closure schemes (see Halliwell [2004] for a review). HYCOM has been configured globally, on basin scales, and regionally.

The $1 / 12^{\circ}(\sim 7 \mathrm{~km}$ mid-latitude resolution) North Atlantic HYCOM system is configured from $28^{\circ} \mathrm{S}$ to $70^{\circ} \mathrm{N}$, including the Mediterranean Sea (see Chassignet et al. [2005] for details). The vertical resolution consists of 26 hybrid layers, with the top layer typically at its minimum thickness of $3 \mathrm{~m}$ (i.e., in fixed coordinate mode to provide near-surface values). In coastal waters, there are 15 sigma-levels, and the coastline is at the 10 $\mathrm{m}$ isobath. The northern and southern boundaries are treated as closed, but are outfitted with $3^{\circ}$ buffer zones in which temperature, salinity and pressure are linearly relaxed toward their seasonally varying climatological values. 


\subsection{Data Assimilation}

The $1 / 16^{\circ}$ and $1 / 32^{\circ}$ global NLOM-based systems [Smedstad et al., 2003; Shriver et al., 2005] assimilated track data from available real-time satellite altimeter observations (GFO and JASON) using an optimal interpolation (OI) deviation SSH analysis with the model field as the first guess and mesoscale covariances calculated from Topex-Poseidon and ERS-2 altimeter data [Jacobs et al., 2001]. A statistical inference technique [Hurlburt et al., 1990] updates all layers of the model based on the analysed SSH deviations, including geostrophic updates of the velocity field outside an equatorial band. The global model is then updated to produce a nowcast using slow insertion to further reduce gravity wave generation. In addition, model deviations from full field MODAS SST analyses are assimilated in the form of heat fluxes.

The $1 / 8^{\circ}$ global NCOM system [Barron et al., 2004, 2005] uses relaxation (i.e., nudging) to assimilate 3-D synthetic temperature and salinity fields generated from MODAS SST analyses and the $1 / 16^{\circ}$ NLOM SSH fields using the MODAS system algorithms and statistics [Fox et al., 2002]. The nudging in NCOM is weak from below the surface to the base of the mixed layer to allow greater model impact on the mixed layer.

The data assimilation in the current $1 / 12^{\circ}$ North Atlantic HYCOM system consists of assimilating daily operational MODAS SSH analyses of available realtime satellite altimeter observations (GFO and JASON) [Chassignet et al., 2005]. The Cooper and Haines [1996] technique is used to project the surface information to the interior of the ocean. A relaxation to the MODAS SST analysis is also included.

All systems provide nowcasts and forecasts at least once a week, with forecasts for 30 days from the global NLOM systems, 5 days from the global NCOM system, and 14 days from the $1 / 12^{\circ}$ Atlantic HYCOM system.

\subsection{The Mean Sea Surface Height}

In order to assimilate the anomalies determined from the satellite altimeter data into the numerical model, it is necessary to know the oceanic mean SSH over the time period of the altimeter observations. Unfortunately, the geoid is not known accurately on the mesoscale. Several satellite missions are either underway or planned to try to determine a more accurate geoid, but until the measurements become accurate to within a few centimeters on scales down to approximately $30 \mathrm{~km}$, one has to define a mean oceanic SSH. At the scales of interest (tens of kilometres), it is necessary to have the mean of major ocean currents and associated SSH fronts sharply defined. This is not feasible from coarse hydrographic climatologies ( $1^{\circ}$ horizontal resolution) and the approach taken by the above systems has been to use a model mean SSH. This requires a fully eddyresolving ocean model which is consistent with hydrographic climatologies and with fronts in the correct position.

For the NLOM-based system, the mean SSH from a global NLOM $1 / 16^{\circ}$ run without data assimilation was compared to the mean dynamic height calculated from available temperature and salinity measurements and then modified with data over the period of the satellites. To help determine the position of the fronts, mean frontal positions from satellite IR plus the variability from satellite altimeter data were also used. Following this effort to accurately determine the mean position of the front, the model mean was modified by moving the SSH features in an elastic way (rubber-sheeting) [Hord, 1982; Clarke, 1990; Carnes at al., 1996] (see Smedstad et al. [2003] for an illustration). The $1 / 8^{\circ}$ global NCOM uses the same mean $\mathrm{SSH}$ and assimilates the $1 / 16^{\circ}$ NLOM SSH fields. The HYCOM-based forecasting system uses a different model mean, one generated by a previous $1 / 12^{\circ}$ North Atlantic simulation performed with the Miami Isopycnic Coordinate Ocean Model (MICOM) (see Chassignet and Garraffo [2001] for a discussion).

\section{COMPARISON TO OCEAN COLOR}

Plates 1-4 compare SSH analyses from the three ocean data assimilative systems which overlie ocean color imagery from SeaWiFS in the Gulf of Mexico. Each Plate is for a different date (July 9, July 19, July 26, and August 8,2003 ) and contains results from the $1 / 16^{\circ}$ global NLOM (8 km resolution in the Gulf of Mexico), the $1 / 32^{\circ}$ global NLOM (4 km resolution), the $1 / 8^{\circ}$ global NCOM (17 km resolution), and the $1 / 12^{\circ}$ Atlantic HYCOM (8 km resolution). These dates correspond to a Loop Current shedding event as well as further interactions between the newly formed ring and the Loop Current. These snapshots clearly illustrate how ocean color has the potential to characterize the performance of each system, but do not allow for a quantitative assessment of the systems. The SeaWiFS imagery is a composite of the most recent cloud-free pixel over the preceding 6 days and is colored prismatically from low (violet) to high (red). Both bright and dark areas of ocean color provide useful information. Dark areas of low chlorophyll $\left(<.1 \mathrm{mg} / \mathrm{m}^{3}\right)$ usually correspond to Caribbean water from outside the Gulf of Mexico and can be seen inside the Loop Current and shed eddies. When the model is in good agreement with SeaWiFS imagery, the SSH contours of the Loop Current and shed eddies capture the dark areas quite 

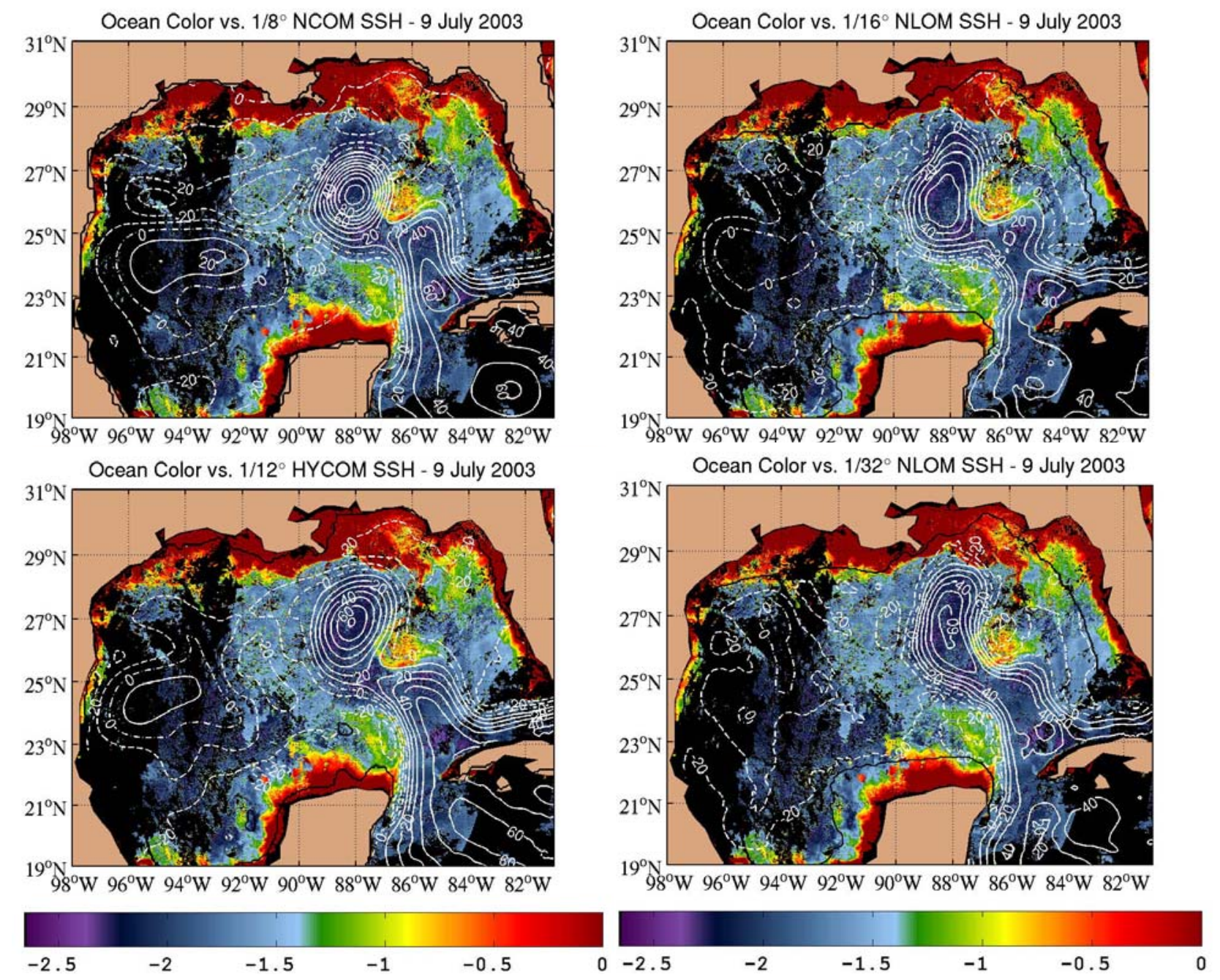

Plate 1: SSH from four ocean data assimilative systems on 09 July 2003 (contour interval of $10 \mathrm{~cm}$ and normalized over the displayed area), overlying ocean color imagery from SeaWiFS (natural log of the concentration in $\mathrm{mg} \mathrm{m}^{-3}$ ). The model land-sea boundary is defined by the black contour line.

well. The mismatches show up clearly and the four-way comparison is very effective in bringing them out. One has to be careful when performing the evaluation, since the overlain SSH contours can occasionally obscure some of the features seen in the imagery. The bright areas of high chlorophyll $\left(>.7 \mathrm{mg} / \mathrm{m}^{3}\right)$, usually generated along the coast in the Gulf of Mexico, tend to be advected into plumes by strong currents but sometimes are also present in the center of cyclonic (counterclockwise) eddies.

09 July 2003: Plate 1 clearly illustrates the final process leading to the separation of a Loop Current ring. Specifically, there is a bright patch of high chlorophyll $\left(\sim .5 \mathrm{mg} / \mathrm{m}^{3}\right)$ that is being advected across the Loop Current as the eddy separates. The four models differ from each other significantly. The NLOM $1 / 16^{\circ}$ does a very good job of capturing the complex pattern of the Loop Current, especially southeast of the bright chlorophyll patch. The soon-to-be shed eddy, however, does not extend as far north as the SeaWiFS imagery suggest. The NLOM $1 / 32^{\circ}$ does a better job in that regard, but the westward front of the Loop Current does not extend sufficiently southwest. The wedge represented by the bright chlorophyll patch is also not well defined in NLOM $1 / 32^{\circ}$. Close examination of NLOM $1 / 16^{\circ}$ and NLOM $1 / 32^{\circ}$ also show that the westward extent of the eastern front of the Loop Current closest to the Florida Keys may be slightly exaggerated in NLOM $1 / 16^{\circ}$. Despite the fact that NCOM $1 / 8^{\circ}$ assimilates the SSH fields of NLOM $1 / 16^{\circ}$, the two nowcasts differ significantly. NCOM $1 / 8^{\circ}$ clearly misses a large portion of the northward extent of the Loop Current and shows a Loop Current ring already well 

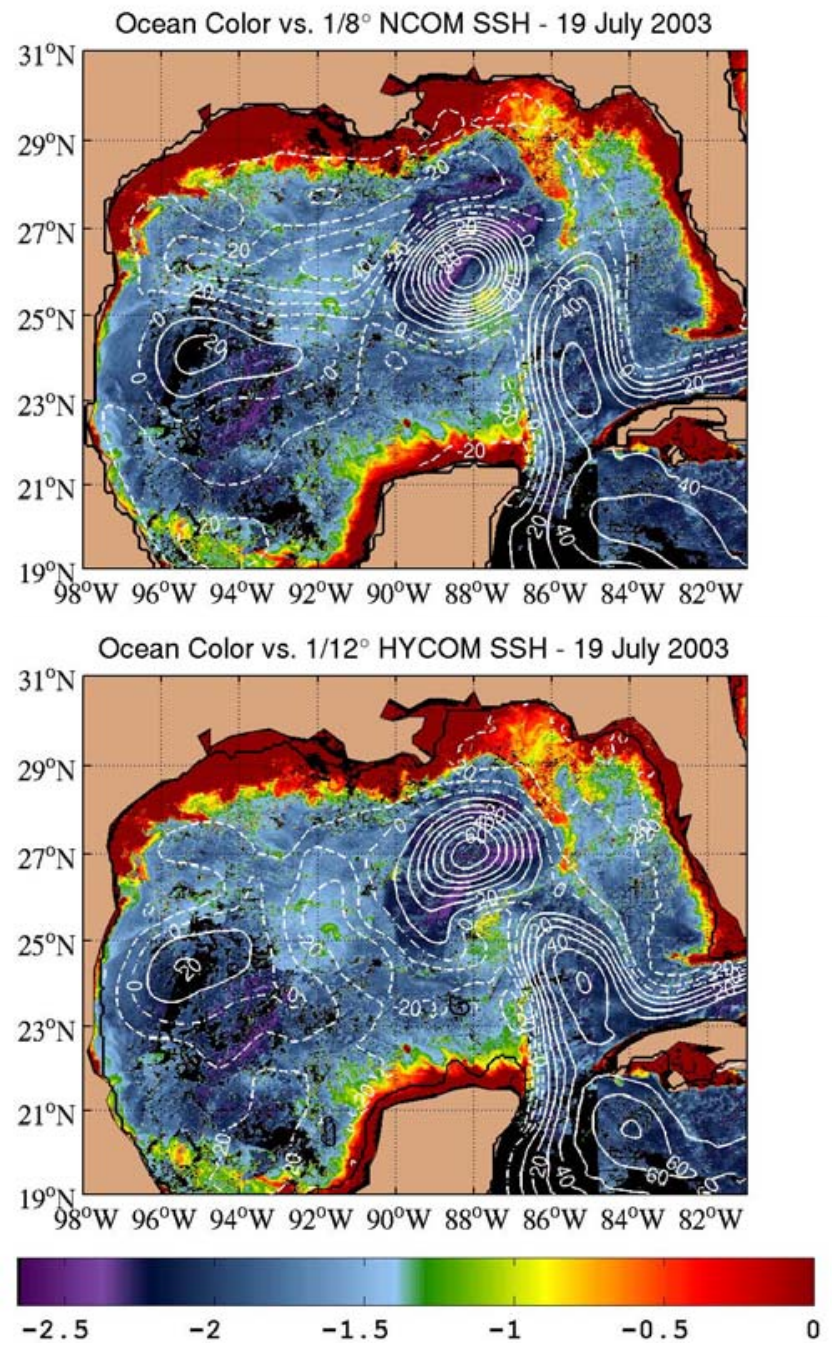
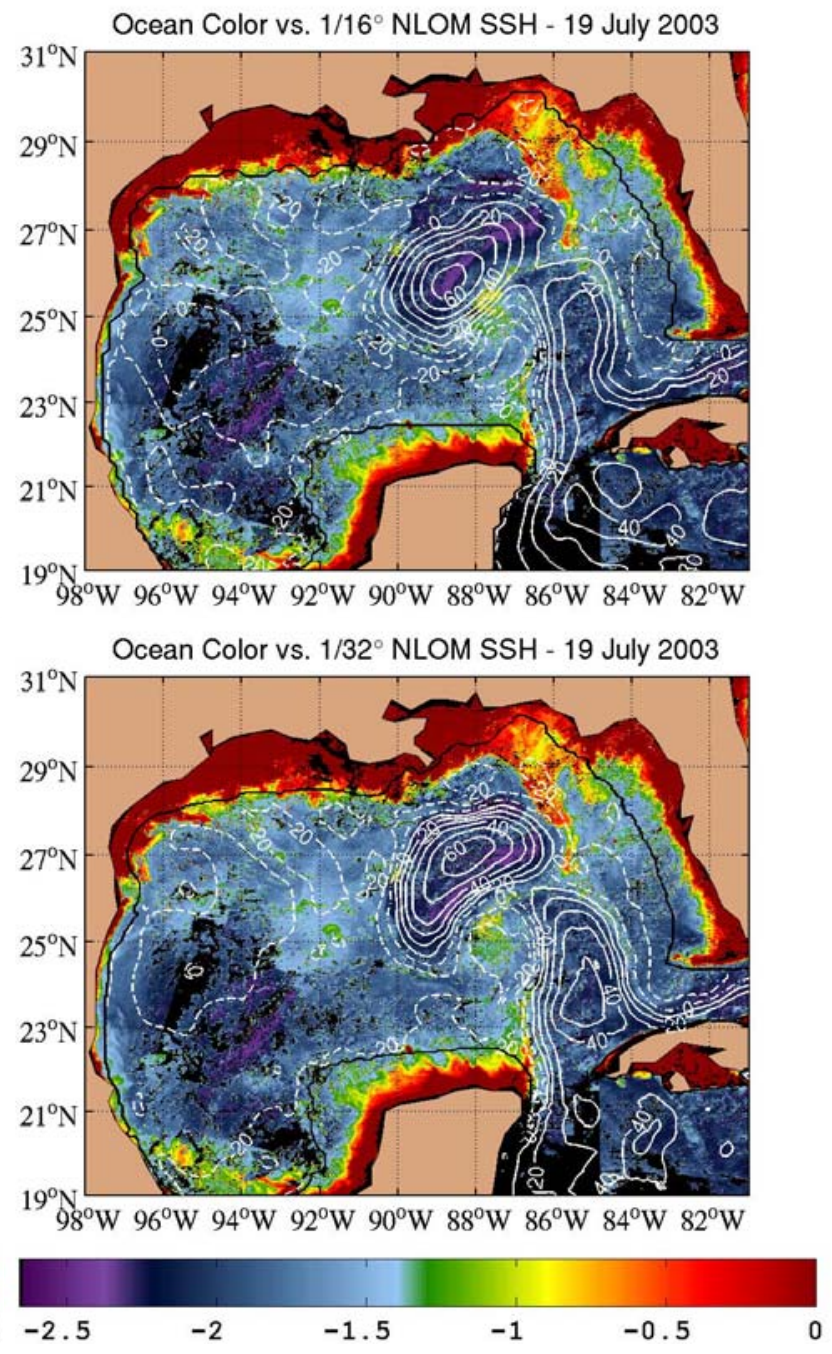

Plate 2: SSH from four ocean data assimilative systems on 19 July 2003 (contour interval of 10 cm and normalized over the displayed area), overlying ocean color imagery from SeaWiFS (natural log of the concentration in $\mathrm{mg} \mathrm{m}^{-3}$ ). The model land-sea boundary is defined by the black contour line.

defined. Part of the bright patch of chlorophyll can actually be seen inside the newly formed ring, a clear indication of the misplacement of the frontal features. The wedge represented by the bright chlorophyll patch is perhaps best represented by HYCOM $1 / 12^{\circ}$ but, as in NLOM $1 / 32^{\circ}$, the western front of the Loop Current does not extend sufficiently far south.

19 July 2003: This snapshot (Plate 2) is especially illustrative, since the SeaWiFS imagery clearly shows a separated Loop Current ring. Furthermore, the irregular shape of the ring is quite challenging for the models. For that specific day, NLOM $1 / 32^{\circ}$ agrees best with the color measurements. Of particular note is the accurate representation of the shape and position of the ring and of the Loop Current as depicted by the low chlorophyll water (deep purple). The HYCOM $1 / 12^{\circ}$ also does quite well at representing these features, but the ring does not extend far enough to the southwest and the Loop Current does not extend far enough to the north. The Loop Current is pretty well represented in both NLOM $1 / 16^{\circ}$ and NCOM $1 / 8^{\circ}$ (except at the neck in NLOM $1 / 16^{\circ}$ ), but both systems fail to place the newly formed ring properly. The location of the circular ring in NCOM $1 / 8^{\circ}$ (already formed on July 09, 2003) shows a large mismatch between the model results and the chlorophyll observations. Additionally, only NLOM $1 / 32^{\circ}$ and HYCOM $1 / 12^{\circ}$ capture the small cyclonic eddy depicted by high chlorophyll on the south side of the Loop Current ring. HYCOM $1 / 12^{\circ}$ is the most successful in depicting a large anticyclonic eddy in the western Gulf with NCOM $1 / 8^{\circ}$ in second place. NLOM $1 / 32^{\circ}$ is the least successful. 

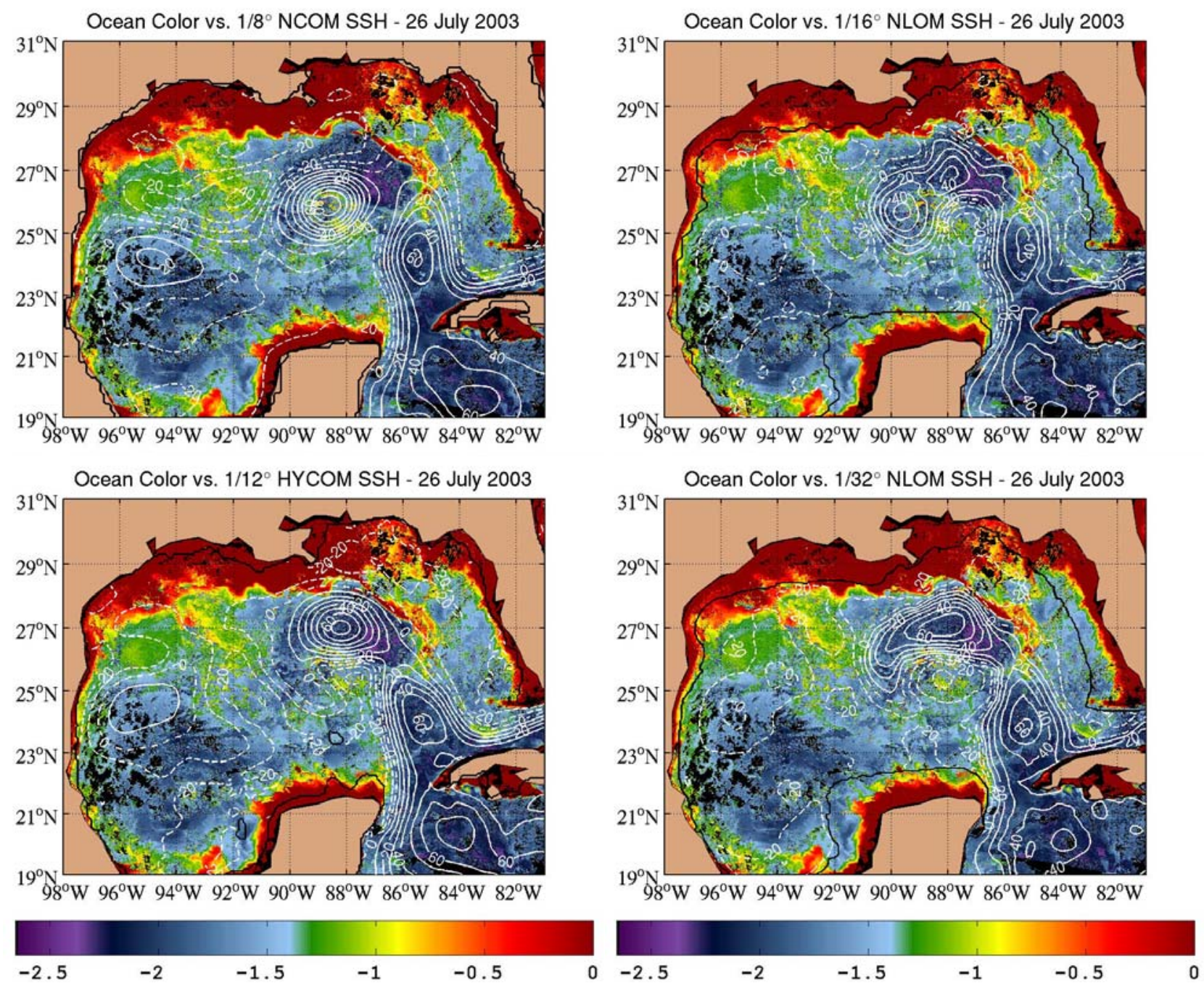

Plate 3: SSH from four ocean data assimilative systems on 26 July 2003 (contour interval of $10 \mathrm{~cm}$ and normalized over the displayed area), overlying ocean color imagery from SeaWiFS (natural log of the concentration in $\mathrm{mg} \mathrm{m}^{-3}$ ). The model land-sea boundary is defined by the black contour line.

26 July 2003: The Loop Current ring that showed as clearly separated on July 19, 2003 is still separated, but showing signs of being recaptured by the Loop Current (Plate 3). NCOM 1/8 ${ }^{\circ}$ shows very little change from 09 July 2003 and fails completely to move the ring northeastward (actually moves it slightly southwestward). The ring's shape remains persistently circular and the eastward position of the Loop Current is misplaced. NLOM $1 / 16^{\circ}$ does show a reattachment of the ring, but the position of both the ring and Loop Current do not agree with the chlorophyll measurements. Again, NLOM $1 / 32^{\circ}$ shows the best agreement with the SeaWiFS imagery, with the eastward edge of the eddy clearly delineated by a long plume of high chlorophyll originating from the Louisiana coast. NLOM $1 / 32^{\circ}$, however, fails to place the eastward frontal position of the Loop Current properly between Cuba and the Florida Keys. HYCOM $1 / 12^{\circ}$ is the only system that accurately positions that specific front. HYCOM $1 / 12^{\circ}$ also places the reattached eddy reasonably well, but is missing some of its lateral extent, especially the eastern area next to the high chlorophyll plume. NLOM $1 / 32^{\circ}$ and HYCOM $1 / 12^{\circ}$ continue to represent the cyclonic eddy depicted by high chlorophyll on the south side of the Loop Current ring. This area of high chlorophyll is overlain by the NCOM $1 / 8^{\circ}$ Loop Current ring and is bisected by the southern side of the NLOM $1 / 16^{\circ}$ Loop Current ring.

08 August 2003: With most of the ring reattached, the Loop Current is now elongated and extends farther to the west and to the north (Plate 4). A fragment of the Loop Current ring remains detached west of the reattached 

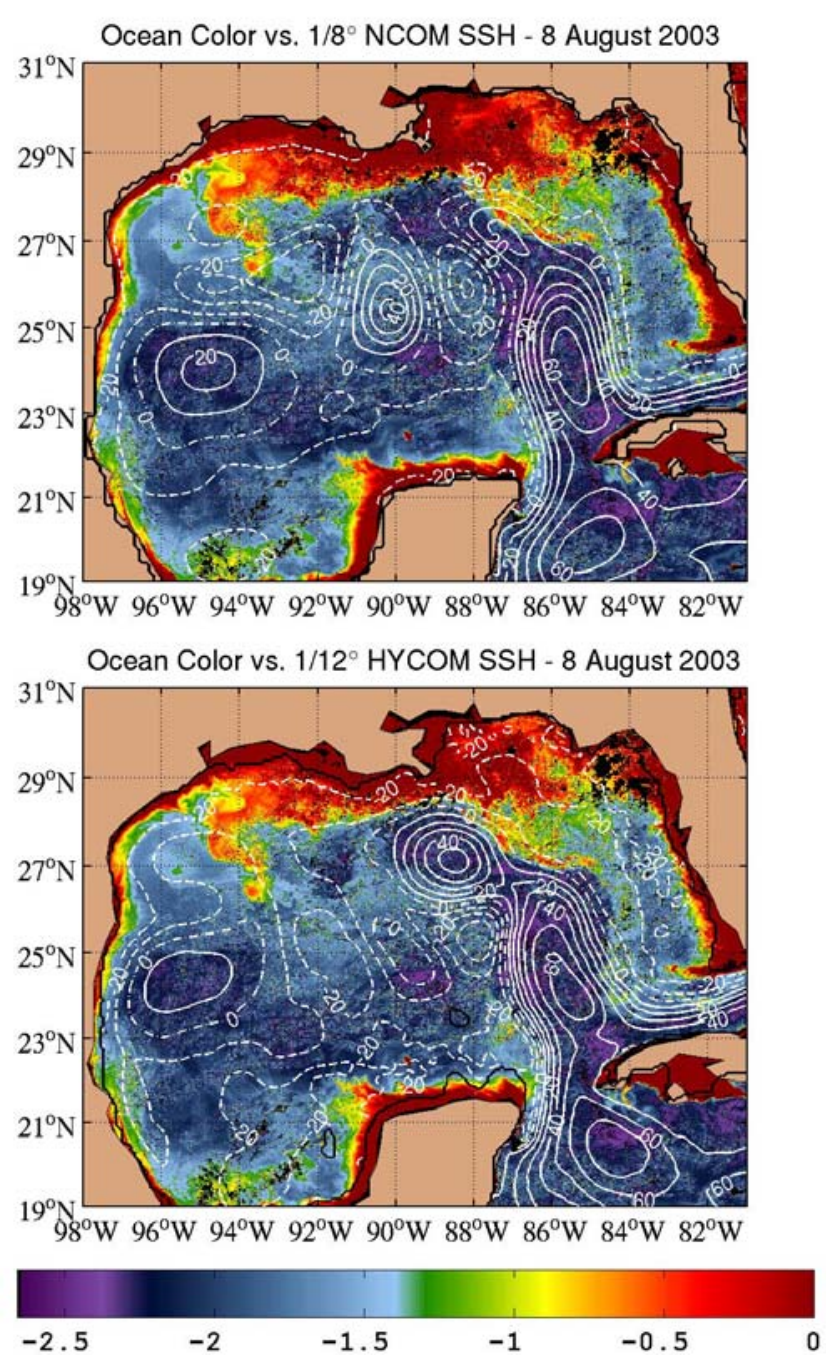
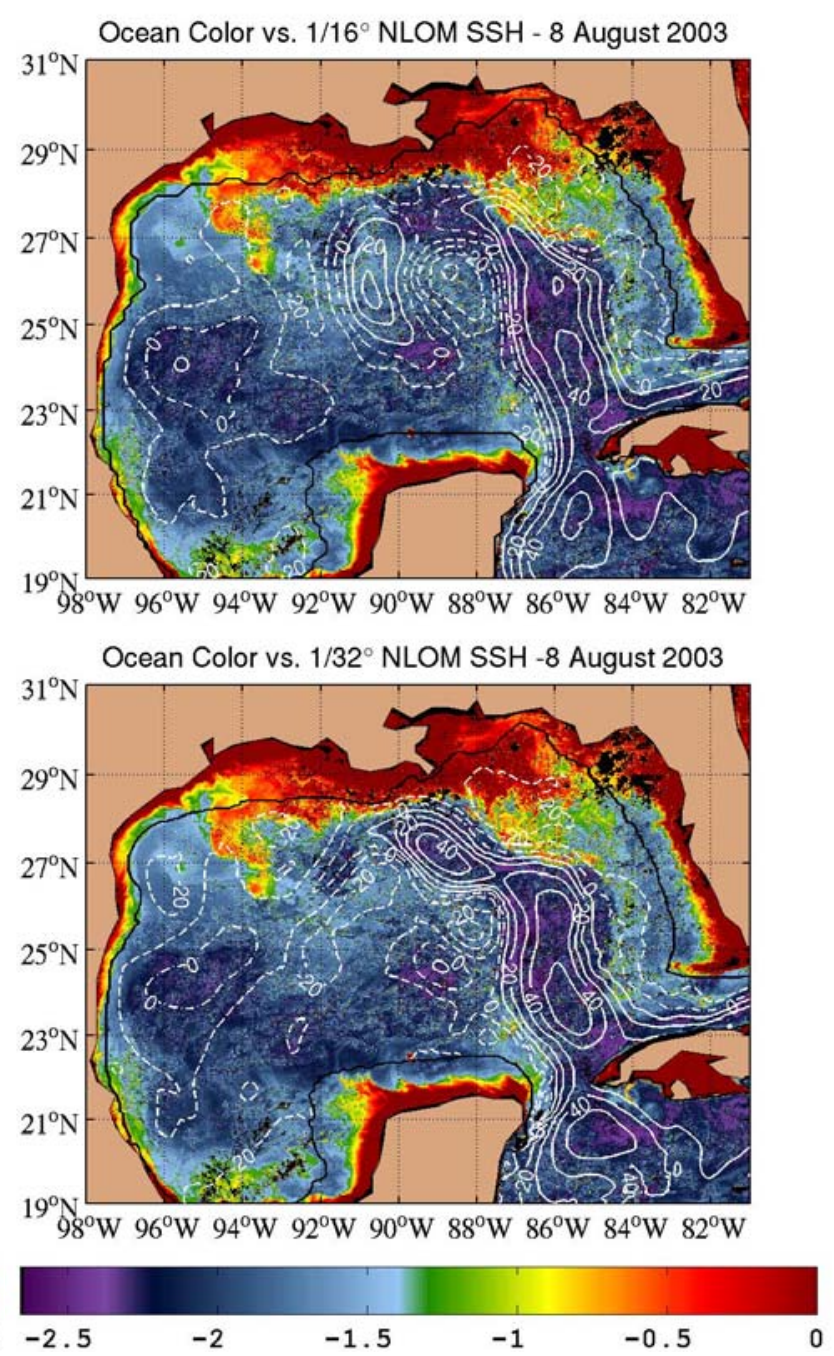

Plate 4: SSH from four ocean data assimilative systems on 08 August 2003 (contour interval of $10 \mathrm{~cm}$ and normalized over the displayed area), overlying ocean color imagery from SeaWiFS (natural log of the concentration in $\mathrm{mg} \mathrm{m}^{-3}$ ). The model land-sea boundary is defined by the black contour line.

portion (small dark area), but is not depicted by any of the systems. In NLOM $1 / 16^{\circ}$, the ring did not remain attached and moved westward of $90^{\circ} \mathrm{W}$. The Loop Current position is reasonably well represented east of $88^{\circ} \mathrm{W}$. The NCOM $1 / 8^{\circ}$ SSH field shows very little agreement between the chlorophyll measurements and the circular ring formed on 09 July 2003, now located farther to the west. In addition, the Loop Current does not extend far enough to the north. Both HYCOM $1 / 12^{\circ}$ and NLOM $1 / 32^{\circ}$ do a good job at capturing the full northwestward extent of the Loop Current. There are some small differences in the representation of the recaptured Loop Current ring. The ring in HYCOM $1 / 12^{\circ}$ is broader and shows more closed SSH contours, but both have nearly the same the ring center location. Both HYCOM $1 / 12^{\circ}$ and NLOM $1 / 32^{\circ}$ fail to correctly place the eastward frontal position of the Loop Current, which is well delineated by high chlorophyll in the observations.

\section{DISCUSSION}

The comparisons performed in section 4 illustrate the value of the SeaWiFS imagery in assessing the ability of three ocean data assimilative systems to map mesoscale ocean features in the Gulf of Mexico. For routine evaluation, quantitative measures of the frontal position of the Loop Current could be established, similar to what is presently done routinely with satellite SST measurements. Specifically, these SeaWiFS measurements can provide additional information on the frontal position of the Loop Current, especially during the summer months when the surface gradient in SST is weak or nonexistent. 

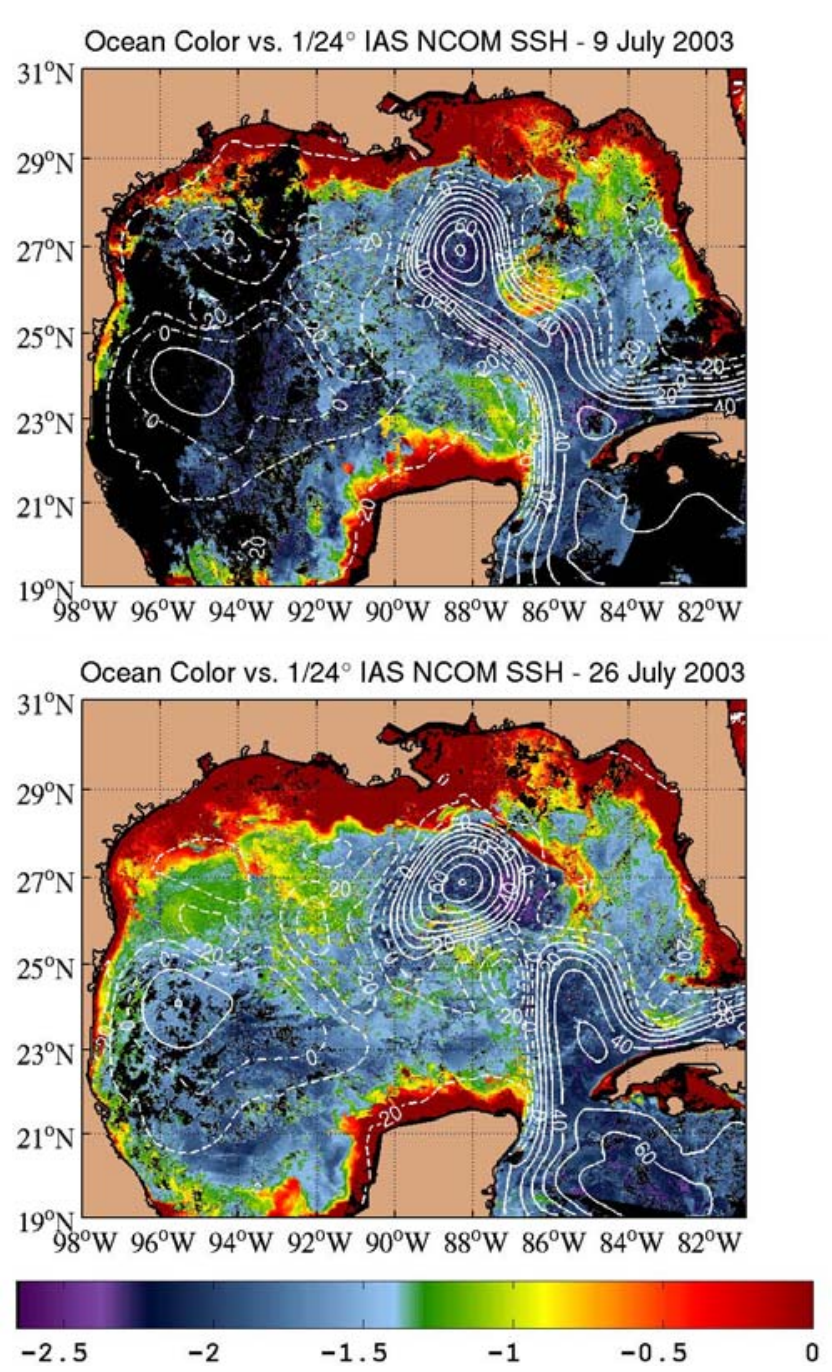
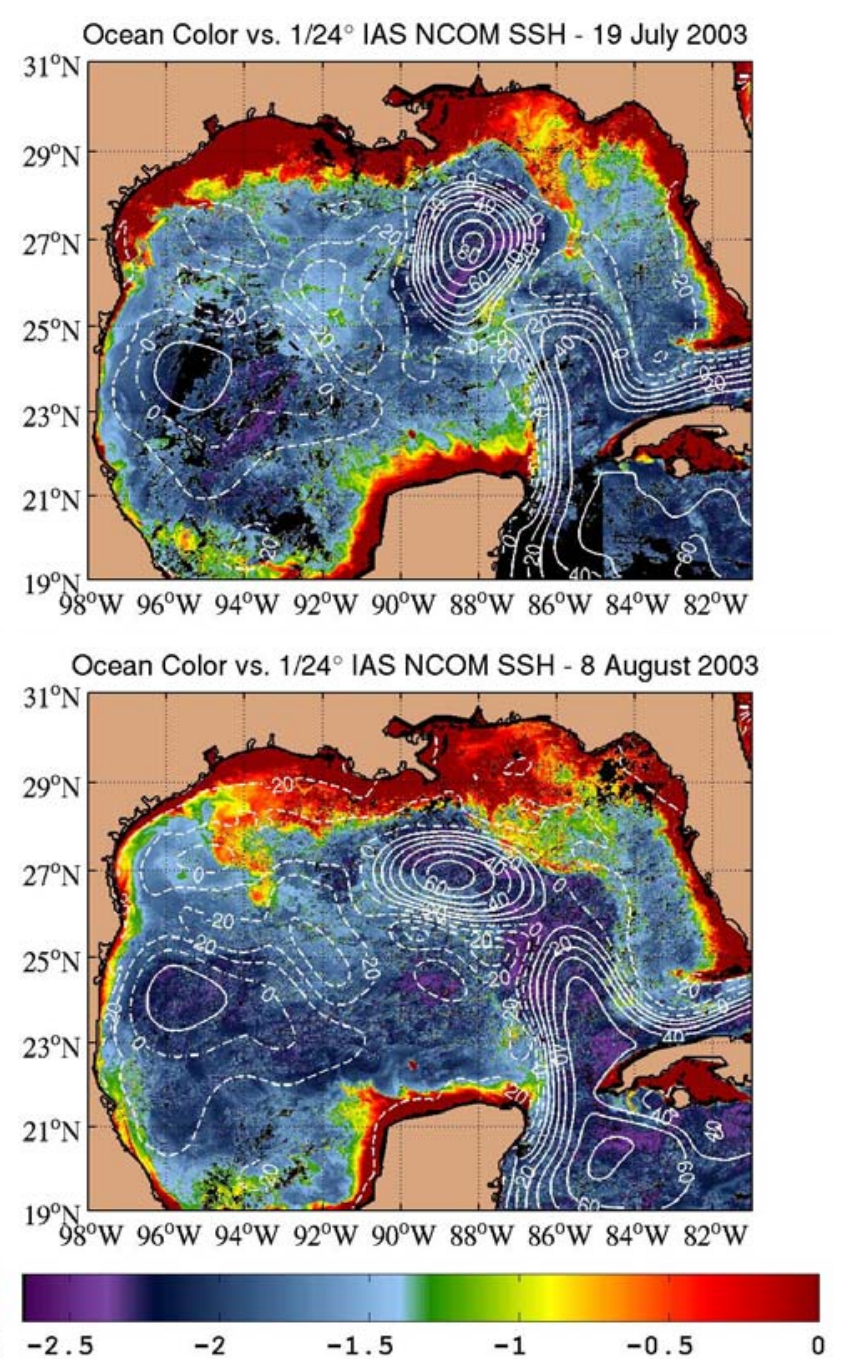

Plate 5: SSH from the 1/24 NCOM data assimilative system on 09, 19, 26 July, and 08 August 2003 (contour interval of $10 \mathrm{~cm}$ and normalized over the displayed area), overlying ocean color imagery from SeaWiFS (natural log of the concentration in mg $\mathrm{m}^{-}$ ${ }^{3}$ ). The model land-sea boundary is defined by the black contour line.

It is apparent from the comparison that horizontal resolution is of importance in properly representing such main features of the Gulf of Mexico as the Loop Current and associated rings, since the NCOM $1 / 8^{\circ}$ system does not perform as well as the NLOM $1 / 16^{\circ}$ system despite assimilating the NLOM $1 / 16^{\circ}$ SSH fields. The NCOM $1 / 8^{\circ}$ system is clearly outperformed by the other three systems, with the high resolution NLOM $1 / 32^{\circ}$ exhibiting the highest skill and the HYCOM $1 / 12^{\circ}$ system running a close second. HYCOM $1 / 12^{\circ}$ performs better overall than NLOM $1 / 16^{\circ}$ despite the fact that they have nearly the same horizontal resolution $(\sim 8 \mathrm{~km})$ in the Gulf of Mexico.

In order to illustrate the impact of horizontal resolution and of assimilating different $\mathrm{SSH}$ fields in NCOM, we now discuss the results (Plate 5) of the
NCOM system using a $1 / 24^{\circ}$ Intra-Americas Sea configuration ( $6 \mathrm{~km}$ grid resolution) [Ko et al., 2003] embedded in the NCOM $1 / 8^{\circ}$ system. The NCOM $1 / 24^{\circ}$ system uses the same data assimilation technology as NCOM $1 / 8^{\circ}$, except that it assimilates the model independent MODAS 2-D SSH analyses [Fox et al., 2002] instead of the SSH fields from the NLOM $1 / 16^{\circ}$ system. Like the other systems, the forcing is from NOGAPS. The open boundary conditions are provided by NCOM $1 / 8^{\circ}$ (one-way coupling) and include sea surface elevation, transport, temperature, salinity, and velocities. Compared to NCOM $1 / 8^{\circ}$, NCOM $1 / 24^{\circ}$ shows an improved representation of the Loop Current ring shedding event on all four days (Plate 5): the separated ring does not remain as circular as it was the case in NCOM $1 / 8^{\circ}$ (although it is still more circular 


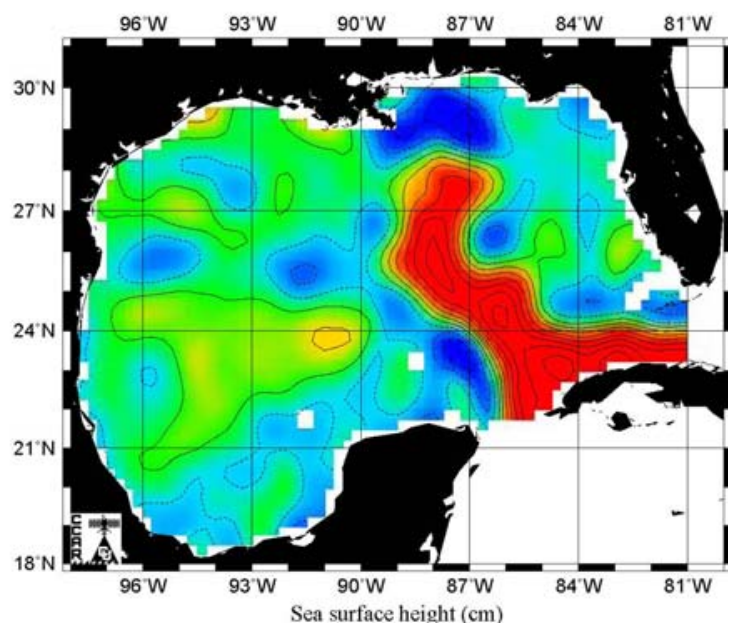

Historical Mesoscale Altimetry - Jul 26, 2003

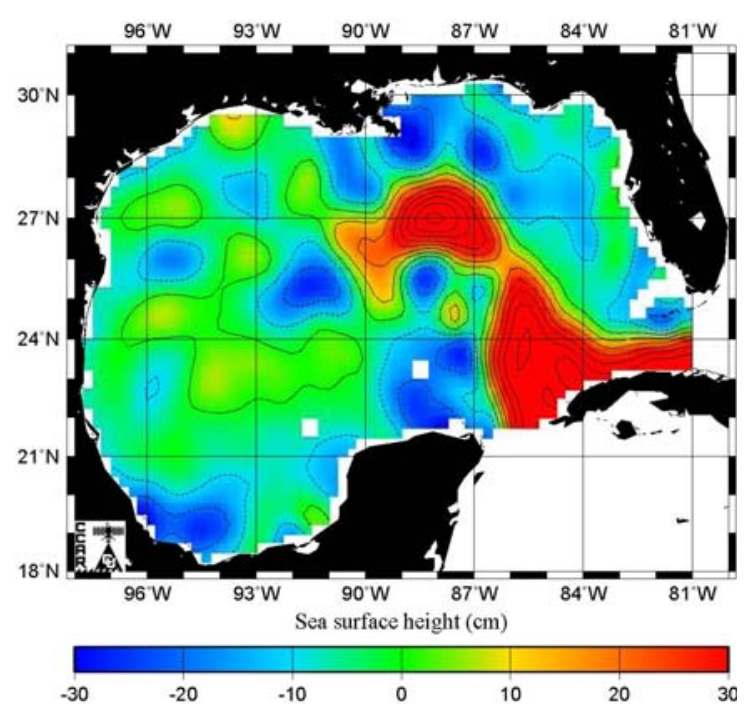

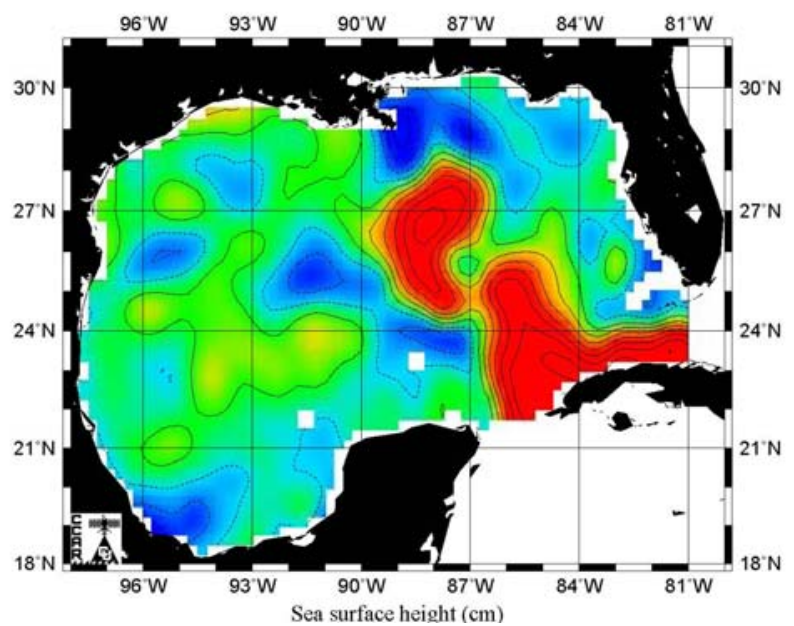

Historical Mesoscale Altimetry - Aug 8, 2003

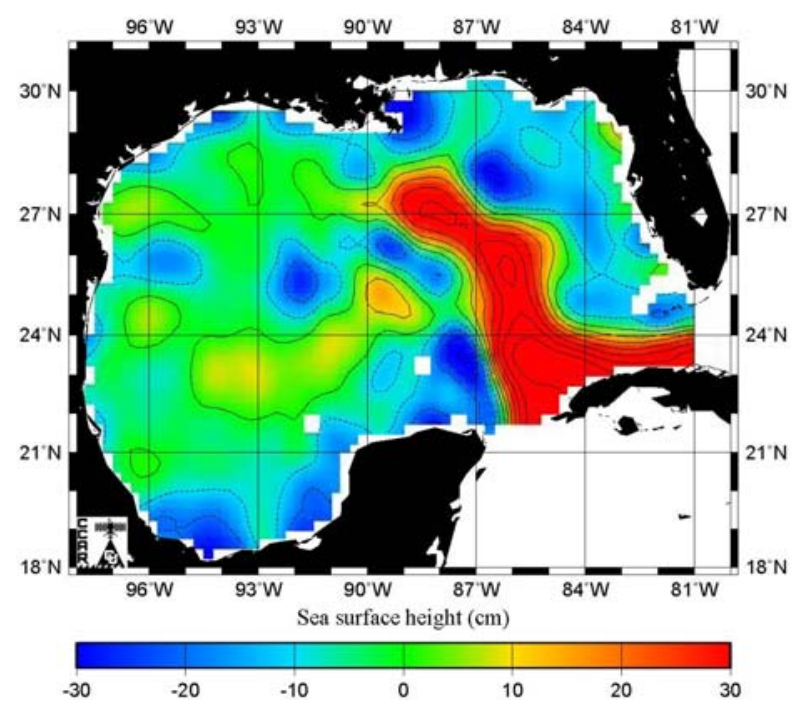

Plate 6: Sea surface height analysis on 09, 19, 26 July and 08 August 2003 (contour interval of $10 \mathrm{~cm}$ ) from the Colorado Center for Astrodynamics Research at the University of Colorado, Boulder [Leben et al., 2002]. The maps are produced from TopexPoseidon, JASON, GFO, and ENVISAT altimeter data anomalies added to a mean SSH field based on a CUPOM model simulation from 1993-1999 (see chapter by Kantha et al. in this volume for details on CUPOM).

than depicted by SeaWIFS) and it is in generally at the right location at the end of the sequence (though too far south by half a degree). However, at this time, NCOM $1 / 24^{\circ}$ has insufficient northward penetration of the Loop Current (less even than NCOM 1/8 ${ }^{\circ}$ ).

Overall, Plates 1-5 demonstrate striking differences in the mapping of the Loop Current and associated eddies. One could have expected a closer agreement between the systems given the fact that they all assimilate SSH fields from the same altimeters. In order to further assess the impact of the data assimilation techniques used by the systems as well as the ability of ocean color to track the observed SSH features, model-independent SSH analyses (except for the SSH mean) performed by the Colorado Center for Astrodynamics Research at the University of Colorado, Boulder [Leben et al., 2002] are presented in Plate 6 for comparison. The maps are produced from Topex-Poseidon, JASON, GFO, and ENVISAT altimeter data anomalies added to a mean SSH field based on a CUPOM model simulation from 1993-1999 (see chapter by Kantha et al. in this volume for details on CUPOM). These hindcast analyses have the potential for higher accuracy because they include altimeter data from two additional satellites, Topex- 
Poseidon and ENVISAT, not then available in the realtime data stream at the Naval Oceanographic Office, the data stream used by all five of the data-assimilative models compared with the ocean color imagery. Although less precise without the overlay, comparison of Plate 6 with the ocean color imagery of Plates 1-5 clearly shows that ocean color and the SSH analyses track the same major ocean features present in the Gulf of Mexico in quite good agreement.

Horizontal resolution of the ocean model is a factor in the accuracy of the mapping by the data assimilative systems, but HYCOM $1 / 12^{\circ}$ also outperforms the NLOM $1 / 16^{\circ}$ and NCOM $1 / 24^{\circ}$, which have similar or finer resolution, showing that other factors (some influenced by resolution) are important as well. Other differences in the prediction systems include the vertical coordinate, the vertical resolution, the bottom topography, and the data assimilation. For data assimilation, the assimilation of SSH and the downward projection of the SSH updates are particularly significant. The NLOM systems assimilate altimeter track data and use the statistical inference technique of Hurlburt et al. [1990] for downward projection which, unlike the other systems, includes projection into the abyssal ocean, a potential advantage in representing baroclinic instability. HYCOM $1 / 12^{\circ}$ uses the Cooper and Haines (1996) scheme for downward projection of SSH updates, while the NCOM systems assimilate SSH (and SST) indirectly via MODAS synthetic T \& S profiles [Fox et al., 2002]. NCOM $1 / 8^{\circ}$ assimilates the NLOM $1 / 16^{\circ}$ SSH fields while HYCOM $1 / 12^{\circ}$ and NCOM $1 / 24^{\circ}$ assimilate the model-independent MODAS2D analyses of SSH anomalies [Fox et al., 2002] operational at NAVOCEANO, but use a different mean SSH, a MICOM mean from an atmosphericallyforced simulation for HYCOM and the surface dynamic height from the MODAS hydrographic climatology for NCOM $1 / 24^{\circ}$.

The simulation skill of the ocean model without data assimilation also strongly influences prediction system skill. This skill is influenced by model resolution and other factors, including those listed earlier. In the Gulf of Mexico, accurate inflow through the Yucatan Channel is critical and may not be strongly constrained by the data assimilation. Accurate inflow transport and realistic vertical and horizontal structure of the inflow are needed, as this influences the northward Loop Current penetration into the basin and the stability of the Loop Current after separation from the Campeche Bank. The inflow includes strong surface trapping with a high speed core on the west side of the channel. The current structure in HYCOM $1 / 12^{\circ}$ [Chassignet et al,, 2005] has shown excellent comparison with observations [Sheinbaum et al., 2002; Abascal et al., 2003] and a strong surface jet on the west side of the channel is indicated by the tightly packed SSH contours in the figures. NLOM $1 / 16^{\circ}$ and NLOM $1 / 32^{\circ}$ show a similar SSH signature for the inflow. NLOM simulations without data assimilation give higher inflow transport and greater surface trapping at $1 / 32^{\circ}$ resolution. The NCOM systems have lower inflow transport, an indication of why the HYCOM and NLOM systems tend to give better agreement with SeaWiFS for the northward Loop Current penetration. Excessive abyssal inflow on the west side of the channel can also inhibit Loop Current penetration [Hurlburt and Thompson, 1980]. NLOM $1 / 16^{\circ}$ has the opposite problem, with an unrealistic westward abyssal current along the northern continental slope due to southward leakage of some flow from the Atlantic Deep Western Boundary Current (DWBC) through the Florida Strait (which does not occur in NLOM $1 / 32^{\circ}$ after modification of the bottom boundary condition). Abyssal currents can advect upper ocean currents where they intersect at large angles [Hurlburt and Thompson, 1980; Hurlburt et al., 1996]. This causes the Loop Current ring to move westward too rapidly (Plate 4).

Another key difference in the systems is their ability to represent baroclinic instability, a phenomenon manifested by contortions of the Loop Current and associated eddies (e.g., noncircular eddies) and by cyclonic eddies on the periphery of the Loop Current and associated anticyclonic rings. This is particularly well represented in the NLOM $1 / 32^{\circ}$ system and is also exhibited in the NLOM $1 / 16^{\circ}$ system. It is seen in the HYCOM $1 / 12^{\circ}$ system, but appears to be inhibited by the assimilation of the relatively smooth modelindependent SSH anomaly analyses. The HYCOM $1 / 12^{\circ}$ and NLOM $1 / 32^{\circ}$ systems also depict the cyclonic eddy on the south side of the Loop Current ring (Plates $2-3$ ) which is missing in the NCOM $1 / 8^{\circ}$ and NCOM $1 / 24^{\circ}$ systems and is poorly represented in the NLOM $1 / 16^{\circ}$ system. In the two NCOM systems, the Loop Current eddy is too circular and the observed contortions of the Loop Current and associated eddies are limited, especially in NCOM $1 / 8^{\circ}$ where the Loop Current ring is much more circular than the NLOM $1 / 16^{\circ}$ ring it assimilated (Plates 1-4). Particularly striking are the differences in HYCOM $1 / 12^{\circ}$ and NCOM $1 / 24^{\circ}$, which both assimilated the same model-independent SSH anomaly analyses. These are associated with the differences in model dynamics, choice of mean SSH, and the related Yucatan inflow (see chapter by Oey et al. in this volume for a comparison between the observed Yucatan Channel flow structure and its representation in six different models). The HYCOM $1 / 12^{\circ}$ results are actually more similar to the NLOM $1 / 32^{\circ}$, the two in best agreement with the SeaWiFS imagery. 


\section{CONCLUSION}

The results of this study illustrate the value of SeaWiFS ocean color imagery in assessing the ability of five ocean data assimilative systems to map mesoscale variability in the Gulf of Mexico. A quantitative assessment was not performed as it would have required evaluating the frontal position of the Loop Current and eddies from the SeaWiFS imagery, a task beyond the scope of this paper.

The SeaWiFS imagery is very effective in monitoring the changes in the mesoscale activity in the Gulf of Mexico, in differentiating the ability of the five systems to map the evolution of the Loop Current and associated warm and cold eddies, and in helping to diagnose specific strengths and weaknesses of the systems. This was made possible by improved compositing methods which effectively removed the clouds and retained ocean features in the surface chlorophyll properties. The imagery provides a unique independent data set for validating numerical models by determining the locations of mesoscale features. Both chlorophyll-rich and chlorophyll-poor regions proved useful. High chlorophyll plumes from the Mississppi River were advected offshore and helped outline the eastern edge of the Loop Current. Elevated chlorophyll was also present in the center of some cyclonic eddies. Dark chlorophyllpoor areas clearly represented the interior of the Loop Current and Loop Current rings.

In addition, the study clearly illustrates that biological responses of the surface waters are strongly linked to the physical events and processes. It also shows the increasing ability of eddy-resolving, data assimilative ocean models to map ocean features and events that are biologically relevant. This capability can help to link observed biological evolution quantitatively to observed circulation processes and events such as upwelling, subduction, advection, convergence, divergence and vertical mixing, a topic that should be the subject of future research.

Acknowledgements: We express our appreciation to Peter Flynn and Brandon Casey at NRL for help with processing the SeaWiFS ocean color imagery and developing the time series shown here. Animations of their work can be seen at http://hycom.rsmas.miami.edu and http://www.ocean.nrlssc.navy.mil/global_nlom. We also would like to thank Ruth Preller, Lakshmi Kantha, and four anonymous reviewers for insightful comments. This research was sponsored by the National Ocean Partnership Program (NOPP), the Office of Naval Research (ONR), and the Operational Effects Programs (OEP) Program Office, PMW 150 through the following projects: NOPP HYCOM Consortium for DataAssimilative Ocean Modeling, NOPP U.S. GODAE: Global Ocean Prediction with the HYbrid Coordinate Ocean Model (HYCOM), 6.1 Dynamics of Low Latitude Western Boundary Currents (ONR), 6.4 Large Scale Ocean Models, 6.4 Ocean Data assimilation, and 6.4 Small Scale Oceanography (all the 6.4 projects sponsored by PMW-150).

\section{REFERENCES}

Abascal, A. J., J. Sheinbaum, J. Candela, J. Ochoa, and A. Badan (2003), Analysis of flow variability in the Yucatan Channel. J. Geophys. Res., 108, doi:10.1029/2003JC001922.

Arnone, R. A., P. Martinolich, R. W. Gould, Jr., M. Sydor, R. Stumpf, and S. Ladner, 1998: Coastal optical properties using SeaWiFS, Proceedings of Ocean Optics XIV, Kailua-Kona Hawaii, 10-13 November.

Arnone R. A. and A. R. Parsons, 2004: Real time use of ocean color remote sensing for coastal monitoring, Chapter 14 in Remote Sensing of Aquatic Coastal Environments, Ed. R. L. Miller, C. E. Del Castillo, B. A. McKee, Kluwer Academic Publishers, Netherlands.

Barron, C. N., A. B. Kara, H. E. Hurlburt, C. Rowley, and L. F. Smedstad, 2004: Sea surface height predictions from the Global Navy Coastal Ocean Model (NCOM) during 1998-2001. J. Atmos. Ocean. Tech., 21, 1876-1893.

Barron, C. N., P. J. Martin, A. B. Kara, R. C. Rhodes, and L. F. Smedstad, 2005: Description and application of the Global Navy Coastal Ocean Model (NCOM), with examination of vertical coordinate system choices. Ocean Modelling, in press.

Bleck, R., 2002: An oceanic general circulation model framed in hybrid isopycnic-cartesian coordinates, Ocean Modelling, 4, 55-88.

Carnes, M. R., D. N. Fox, R. C. Rhodes, and O. M. Smedstad, 1996: Data assimilation in a North Pacific Ocean monitoring and prediction system. In Modern Approaches to Data Assimilation in Ocean Modeling, Ed. P. Malanotte--Rizzoli, Elsevier, 61, 319-345.

Chassignet, E. P., and Z. D. Garraffo, 2001: Viscosity parameterization and the Gulf Stream separation. In From Stirring to Mixing in a Stratified Ocean. Proceedings 'Aha Huliko'a Hawaiian Winter Workshop. U. of Hawaii. January 15-19, 2001. P. Muller and D. Henderson, Eds., 37-41.

Chassignet E. P., H. Arango, D. Dietrich, T. Ezer, M. Ghil, D. B. Haidvogel, C.-C. Ma, A. Mehra, A. M. Paiva, Z. Sirkes, 2000: DAMEE-NAB: The base experiments. Dyn. Atmos. Oceans, 32, 155-183. 
Chassignet, E. P., L. T. Smith, G. R. Halliwell, and R. Bleck, 2003: North Atlantic simulation with the HYbrid Coordinate Ocean Model (HYCOM): Impact of the vertical coordinate choice, reference density, and thermobaricity. J. Phys. Oceanogr., 33, 25042526.

Chassignet, E. P., H. E. Hurlburt, O. M. Smedstad, G.R. Halliwell, P. J. Hogan, A. J. Wallcraft, R. Baraille, and R. Bleck, 2005: The HYCOM (HYbrid Coordinate Ocean Model) data assimilative system. $J$. Mar. Sys., in press.

Clarke, K. C., 1990: Analytical and Computer Cartography, Prentice Hall, 290 pp.

Cooper, M. and K. Haines, 1996: Altimetric assimilation with water property conservation. J. Geophys. Res., 101, 1059-1077.

Fox, D. N., W. J. Teague, C. N. Barron, M. R. Carnes, and C. M. Lee, 2002: The Modular Ocean Data Assimilation System (MODAS). J. Atmos. Oceanic Tech., 19, 240-252.

Halliwell, G. R., 2004: Evaluation of vertical coordinate and vertical mixing algorithms in the HYbrid Coordinate Ocean Model (HYCOM). Ocean Modelling, 7, 285-322.

Hellerman, S., and M. Rosenstein, 1983: Normal monthly wind stress over the World Ocean with error estimates. J. Phys. Oceanogr., 13, 1093-1104.

Hogan, T. F. and T. E. Rosmond, 1991: The description of the U.S. Navy Operational Global Atmospheric Prediction System's spectral forecast model. Mon. Wea. Rev. 119, 1786-1815.

Hord, R. M., 1982: Digital Image Processing of Remotely Sensed Data. Academic Press, 256 pp.

Hurlburt, H. E., 1984: The potential for ocean prediction and the role of altimeter data. Mar. Geod., 8, 17-66.

Hurlburt, H. E., and J. D. Thompson, 1980: A numerical study of Loop Current intrusions and eddy shedding. J. Phys. Oceanogr., 10, 1611-1651.

Hurlburt, H. E., D. N. Fox, and E. J. Metzger, 1990: Statistical inference of weakly--correlated subthermocline fields from satellite altimeter data. $J$. Geophys. Res., 95, 11,375-11,409.

Hurlburt, H. E., A. J. Wallcraft, W. J Schmitz Jr., P. J. Hogan, and E. J. Metzger, 1996: Dynamics of the Kuroshio/Oyashio current system using eddyresolving models of the North Pacific Ocean. $J$. Geophys. Res., 101, 941-976.

Jacobs, G. A., C. N. Barron, and R. C. Rhodes, 2001: Mesoscale characteristics. J. Geophys. Res., 106, 19,581-19,595.

Kantha, L., J.-K. Choi, K. J. Schaudt, and C. K. Cooper, 2005: A regional data-assimilative model for operational use in the Gulf of Mexico. In AGU
Monograph "New developments in the circulation of the Gulf of Mexico".

Kara, A.B., C.N. Barron, P.J. Martin, L.F. Smedstad, and R.C. Rhodes, 2005: Validation of interannual simulations from the $1 / 8^{\circ}$ Global Navy Coastal Ocean Model (NCOM). Ocean Modelling, in press.

Ko, D.-S., R.H. Preller, and P.J. Martin, 2003: “An experimental real-time Intra-Americas Sea ocean nowcast/forecast system for coastal prediction," Prceedings of the American Meteorological Society's Conference on Coastal Atmospheric and Oceanic Processes and Prediction, Seattle, WA, pp. 97-103.

Leben, R. R., G. H. Born, and B. R. Engebreth, 2002: Operational altimeter data processing for mesoscale monitoring. Marine Geodesy, 25, 3-18.

Lee, Z. P., K. L. Carder, G. Stewart, T. G. Peacock, C. O. Davis, and J. S. Patch, 1998: An empirical algorithm for light absorption by ocean water based on color. J. Geophys. Res., 110, 27,967-27,977.

Oey, L.-Y., T. Ezer, and H.-C. Lee, 2005: Loop Current, rings and related circulation in the Gulf of Mexico: A review of numerical models and future challenges. In AGU Monograph "New developments in the circulation of the Gulf of Mexico".

O’Reilly, J. S. Maritorena, B. Mitchell, D. Siegel, K. Carder, S. Garver, M. Kahru, C. McClain. 1998: Ocean color chlorophyll algorithms for SeaWiFS. J. Geophys. Res.. 103, 24,937-24,953.

Rosmond, T. E., J. Teixeira, M. Peng, T. F. Hogan, and R. Pauley, 2002: Navy Operational Global Atmospheric Prediction System (NOGAPS): Forcing for ocean models. Oceanography, 15, 99-108.

Sheinbaum, J., J. Candela, A. Badan, J. Ochoa, 2002: Flow structure and transport in Yucatan Channel. Geophys. Res. Lett., 29(3), 10.1029/2001GL0139990.

Shriver, J. F., H. E. Hurlburt, O. M. Smedstad, A. J. Wallcraft and R. C. Rhodes, 2005: Real-time global ocean prediction at $1 / 32^{\circ}$ resolution and value added over $1 / 16^{\circ}$ resolution. J. Mar. Sys., in press.

Smedstad, O. M., H. E. Hurlburt, E. J. Metzger, R. C. Rhodes, J. F. Shriver, A. J. Wallcraft and A. B. Kara, 2003: A real-time $1 / 16^{\circ}$ global ocean nowcast/forecast system. J. Mar. Sys., 40-41, 341-361.

Wallcraft, A. J., A. B. Kara, H. E. Hurlburt, and P. A. Rochford, 2003: The NRL Layered Ocean Model (NLOM) with an embedded mixed layer sub--model: Formulation and tuning. J. Atmos. Oceanic Technol., 20, 1601-1615.

Willebrand, J., B. Barnier, C. Boening, C. Dieterich, P. Herrmann, P.D. Killworth, C. LeProvost, Y. Jia, J.-M. Molines, and A New, 2001: Circulation characteristics in three eddy-permitting models of the North Atlantic. Prog. Oceanogr., 48, 123-161. 